\title{
Cádiz, la insurgencia y la crisis del señorío jurisdiccional en Nueva España. El caso de la Villa de Charo, 1808-1825
}

\author{
Cadiz, Insurgency and the Crisis in Jurisdictional Lordship in New Spain. \\ The Case of Villa de Charo, 1808-1825
}

\section{Moisés Guzmán Pérez}

UNIVERSIDAD MICHOACANA DE SAN NICOLÁS DE HIDALGO, moisesguzmanp@hotmail.com

Este trabajo profundiza en las contradicciones, los cambios y las continuidades que experimentó la villa de Charo durante la crisis política de la Monarquía española y el proceso de emancipación americano, fuertemente relacionados con el impacto del liberalismo hispánico. Se busca superar una visión historiográfica tradicional, que de manera exclusiva vinculaba la historia de esa población con el legendario encuentro de Miguel Hidalgo y José María Morelos, ocurrido en aquel lugar el 20 de octubre de 1810. En este artículo podemos observar las consecuencias que ocasionó el cambio de estatus político que sufrió la villa, al pasar de corregimiento a tenencia de Valladolid, así como los rezagos en el aspecto social y económico ocasionados por 10 años de guerra. La investigación está apoyada en fuentes documentales de archivo no publicadas hasta ahora y en una bibliografía especializada sobre la guerra insurgente y la mutación que se vivió en esos años.

PaLABRas ClaVE: Charo Matlatzinco, señorío jurisdiccional, guerra de independencia, Cortes de Cádiz, liberalismo español.

This text delves into the contradictions, changes and continuities that Villa de Charo experienced during the crisis of the Spanish Monarchy and the process of American emancipation, two processes closely-related to the impact of Hispanic liberalism. It seeks to go beyond the traditional historiographical vision that linked the history of this locality exclusively to the fabled meeting of Miguel Hidalgo and José María Morelos that took place there on October 20,1810. The article highlights the consequences of the change in the village's political status, as it ceased to be a corregimiento and was brought under the jurisdiction of Valladolid, as well as the social and economic setbacks caused by 10 years of constant warfare. Research was based on previously unpublished documental and archival sources, and on specialized bibliography dealing with the war of insurgency and the changes that occurred during those years.

KeYwORDs: Charo Matlatzinco, jurisdictional lordship, war of independence, Courts of Cadiz, Spanish liberalism.

Fecha de recepción del artículo: 1 de julio de 2015 / Fecha de aprobación: 28 de septiembre de 2015 / Fecha de recepción de la versión final: 16 de marzo de 2016 
n este artículo ${ }^{1}$ nos ocuparemos de un pueblo del Marquesado del Valle que en 1808, luego de las abdicaciones de la familia real en Bayona, experimentó mutaciones importantes en su régimen jurídico. Esta afectación se dio de tres maneras: primero, en 1809 mediante el "secuestro" de los bienes y rentas del Marquesado por parte de la Junta Suprema Central en favor de la Corona; después, a través de la guerra insurgente de 1810, cuyo estallido generó procesos históricos muy complejos que se están revisando actualmente y en los cuales participaron actores sociales de extracción muy diversa; y, finalmente, como resultado de las discusiones de las Cortes extraordinarias reunidas en Cádiz, cuyos diputados decretaron en agosto de 1811 la abolición de los seńoríos jurisdiccionales.

\section{LOS TRASTORNOS DE I 809}

Aunque la crisis política de la Monarquía española comenzó propiamente con las abdicaciones de la familia real en Bayona en 1808, las consecuencias en el caso del Marquesado del Valle se reflejaron varios meses después. En efecto, el 12 de octubre de 1809, la Secretaría del Despacho Universal de Real Hacienda expidió una orden de la Junta Suprema Central que decía: que en vista de que Diego Pignatelli duque de Terranova y Monteleón, marqués del Valle, fungía como embajador en París puesto por Joaquín Murat, rey de Nápoles, se le secuestrara inmediatamente dicho Marquesado como heredero de Hernán Cortés y se pusieran en cajas reales, remitiendo a la Corona tanto los productos devengados y que se devengasen, como todas las pertenencias de cualquier clase que pudiera haber. ${ }^{2}$ En la

\footnotetext{
${ }^{1}$ Este artículo es resultado del Seminario: Cádiz y Nueva España. Contextos, diálogos y trascendencias: Michoacán, Guanajuato y San Luis Potosí, auspiciado por la Universidad de Guanajuato y dirigido por la doctora Graciela Bernal Ruiz en el transcurso de 2012 y 2013 en distintas sedes académicas. Agradezco los comentarios, críticas y sugerencias vertidas en las sesiones por mis colegas Ma. Isabel Monroy, Brian Connaughton, Graciela Bernal, José Eduardo Vidaurri, Carlos Armando Preciado, José Elías Guzmán y en su momento José Antonio Serrano.

${ }^{2}$ Lucas Alamán, Historia de Méjico. Desde los primeros movimientos que prepararon su independencia en el año de 1808 hasta la época presente, Colección Clásicos de la Historia
} 
capital de Nueva España, tocó al virrey Francisco Xavier Lizana y Beaumont tratar de hacer efectivo dicho embargo. Dice Bustamante que Lizana

recibió órdenes de la Junta Central para embargar los bienes que suponía existiesen del marqués de Branciforte y del duque de Terranova, por haberse adherido al partido de Napoleón; mas reconvenidos por la exhibición los apoderados del primero, principalmente el director del tabaco don Silvestre Díaz de la Vega, con quien llevó la más estrecha amistad, sólo entregó un cajón de conchas que tenía en su poder y varios penachos de los caballos de su coche, inservibles [...] En cuanto a las órdenes relativas al duque de Terranova, se cometió una injusticia, pues se mandaron extraer de la tesorería del Estado setecientos mil pesos que tenían allí buenos de sus fincas, queriendo que el gobernador los entregase a fuer de buen patriota; respondió que él lo era; pero en el caso sólo se tenía como un depositario de aquel dinero y no podía disponer de él; que si se le exigía por la fuerza él cedería a ella. De hecho se exigió el dinero, que aún lo debe el rey de España, con más cuarenta mil pesos pertenecientes al hospital de Jesús. Por lo respectivo a la confiscación de bienes, se opuso el fiscal Zagarzurieta porque consideró que era preciso oír a la parte del duque, el cual, aunque estaba al servicio de Napoleón, se consideraba súbdito suyo, pues residía en la corte de Nápoles cuyo trono había ocupado Murat y antes que él José Napoleón. Esta resistencia del fiscal contuvo los efectos de tan bárbaro decreto. ${ }^{3}$

José María Laso, oficial de las cajas reales, y el doctor Manuel de la Bodega y Mollinedo, oidor de la Real Audiencia, fueron las personas comisionadas para concretar el secuestro de los bienes del duque de Terranova. Señala Alamán que mientras dicho embargo duró, tanto el producto de dichas cajas como lo tomado por el gobierno virreinal, constituyeron el principal crédito del duque contra el go-

de México, tomo I, edición facsimilar de la de 1849-1952, precedido de "Alamán historiador” por Moisés González Navarro (México: Fondo de Cultura Económica, Instituto Cultural Helénico, 1985), 307.

${ }^{3}$ Carlos María de Bustamante, Los tres siglos de Méjico durante el gobierno español hasta la entrada del Ejército Trigarante. Obra escrita en Roma por el padre Andrés Cavo, de la Compañia de Jesús. Publicada con notas y suplemento por el licenciado... (México: Imprenta de J. R. Navarro, Editor, 1852), 262. 
bierno español, que en varias ocasiones trataría de hacer valer. ${ }^{4}$ En cuanto a los corregidores, Alanís Boyso menciona que durante el secuestro sólo hubo un nombramiento en abril de 1810 concedido por el virrey Lizana y Beaumont a Agustín Arozqueta, con el cargo de subdelegado de San José de Toluca y su jurisdicción. ${ }^{5}$

Como era de esperarse, los efectos de estas disposiciones tardaron en reflejarse en la villa de Charo - población que formaba parte de dicho Marquesado y que había experimentado cambios importantes a raíz de la implementación del sistema de intendencias-; primero, por el tiempo que implicaba tomar medidas a distancia sobre el gobierno y administración de las distintas jurisdicciones que conformaban el Marquesado, ya fuera para ratificar o sustituir en el cargo al corregidor Antonio Abad Rosel; y segundo, por la insurrección armada que comenzó el cura Miguel Hidalgo y Costilla en la congregación de Dolores, la madrugada del 16 de septiembre de 1810 y que desvió la atención del gobierno.

\section{LA INSURRECCIÓN DE I 8 IO}

Pedro José Sotelo, uno de los primeros soldados de la insurgencia señala en sus Memorias que cuando las fuerzas de Hidalgo provenientes de Guanajuato pasaron por la villa de Charo con destino a Valladolid, hubo gente del lugar que se sumó a su "ejército", como había sucedido en Irapuato, Valle de Santiago, Salvatierra, Acámbaro, Zinapécuaro e Indaparapeo. Esto ocurrió el 17 de octubre a eso de las ocho treinta o nueve de la mańana, poco después de que Hidalgo ordenara al canónigo Sebastián de Betancourt preparar su recibimiento en Valladolid. Un contingente de cerca de $50 \mathrm{mil}$ hombres le seguían; unos miles iban a caballo y la gran mayoría a pie empuñando palos, lanzas, ondas y machetes, portando en sus sombreros una estampilla impresa con la imagen de la guadalupana. ${ }^{6}$

${ }^{4}$ Alamán, Historia, 308.

${ }^{5}$ José Luis Alanís Boyso, Corregidores de Charo. Apuntes para su estudio 1590-1810, Colección Biblioteca Enciclopédica del Estado de México (Toluca: Editorial Libros de México 1976), 45, 77, 138.

6 "Memorias del último de los primeros soldados de la independencia, Pedro José 
Tres días después, el jefe insurgente salió de Valladolid con dirección a la Ciudad de México. El número de sus partidarios ascendía ya a cerca de 80 mil personas entre las que se encontraban cientos de mujeres mulatas, indias y mestizas que seguían a sus maridos, cargando a sus nińos con un rebozo a la espalda. De nueva cuenta Hidalgo hizo parada en Charo; ya de camino para Indaparapeo, fue alcanzado por José María Morelos y Pavón, uno de sus antiguos discípulos en el Colegio de San Nicolás, y

habiéndole prevenido que lo acompañase hasta Indaparapeo, aquí le aseguró que los motivos que tenía para aquel movimiento o Revolución eran, los de la Independencia a que todos los americanos se veían obligados pretender, respecto a que la ausencia del rey en Francia les proporcionaba coyuntura de lograr aquélla; que a consecuencia admitió el que responde una comisión que Hidalgo le confirió en que terminantemente decía:

Por el presente comisiono en toda forma a mi lugar teniente el bachiller don José Maria Morelos, cura de Carácuaro, para que en la Costa del Sur, levante tropas, procediendo con arreglo a las instrucciones verbales que le he comunicado.

Que éstas, fueron las de que por todos los lugares que pasara se encargara y recibiera el gobierno y las armas que existían, encargando aquél nuevamente al sujeto que lo obtenía no siendo europeo, bajo las circunstancias que le parecieren, y que siéndolo le embargase sus bienes para fomento y pago de tropas, cuya circunstancia debería observar con cualquier europeo que aprehendiese, remitiendo su persona a la intendencia más inmediata.

Que también le encargó la toma de Acapulco, cuyo objeto como principal le obligó a Hidalgo a darle al exponente la comisión por el rumbo de la Costa del Sur. ${ }^{7}$

Hasta Charo llegaron las noticias de la toma de Valladolid por las fuerzas insurgentes. Es muy probable que en aquella villa hubiesen

Sotelo. 1874", en Colección de documentos para la historia de la guerra de independencia de México de 1808 a 1821, tomo II, núm. 178, edición facsimilar de 1877-1882, Juan E. Hernández y Dávalos (México: Instituto Nacional de Estudios Históricos de la Revolución Mexicana, Comisión Nacional para las celebraciones del 175 Aniversario de la Independencia Nacional y 75 Aniversario de la Revolución Mexicana, 1985).

7 "Primera declaración del señor Morelos", México, 28 de noviembre de 1815, en Colección de documentos, tomo vi, núm. 42, 18. 
circulado en forma manuscrita varios de los documentos expedidos por José María Ansorena, como intendente de provincia, brigadier y comandante de las armas, así como por Hidalgo en su calidad de capitán general de las fuerzas insurgentes. Decimos esto porque en la correspondencia que José de la Cruz sostuvo con el virrey Francisco Xavier Venegas a principios de enero de 1811, le remitió una carta original del juez de Charo con varias proclamas y documentos insurgentes, a los cuales el mencionado juez no había dado curso. ${ }^{8}$

Aunque no los mencionan, suponemos que se trata del bando de abolición de la esclavitud del 19 de octubre de 1810 que se mandó publicar "para que llegue a noticia de todos"; el oficio que Ansorena remitió al corregidor de Charo comunicándole el nombramiento que le había extendido Hidalgo como intendente corregidor de la provincia, motivo por el cual a partir de ese momento sería a él a quien Rosel tendría que dirigirse como nueva autoridad; ${ }^{10}$ el bando de Ansorena que prohibía la extracción de ganado y semillas de Valladolid con destino a la capital de la Nueva Espańa, y que ordenó circular por la provincia; ${ }^{11}$ el manifiesto de Hidalgo refutando las acusaciones del Tribunal de la Inquisición, que se dio a conocer de forma manuscrita e impresa; ${ }^{12}$ la orden que dieron el intendente Ansorena y el cacique Pedro Rosales a los pueblos de Charo, Indaparapeo, Tzitzio, Copuyo, Santiago, Senguio y Patámbaro de tener prevenidos a hombres honderos para enfrentar cualquier circunstancia; ${ }^{13}$ y, por último, la orden que le dio Ansorena al corregidor de Charo de prevenir a los indios de la villa para hacer frente a los soldados del rey que se aproximaban a Valladolid. ${ }^{14}$

No se sabe hasta ahora cuál fue la postura que asumió el corregidor Rosel ante la insurrección de Hidalgo y si atendió el llamado de Anso-

${ }^{8}$ AGN, Operaciones de Guerra, vol. 146, exp. 13, fs. 37-40. José de la Cruz a Venegas, Valladolid, enero de 1811.

${ }^{9}$ Moisés Guzmán Pérez, Miguel Hidalgo y el gobierno insurgente en Valladolid, Colección Bicentenario de la Independencia, núm. 9, tercera edición actualizada (Morelia: Instituto de Investigaciones Históricas, UMSNH, 2011), 257-258,

${ }^{10}$ Ibid., 262.

${ }^{11}$ Ibid., 279.

${ }^{12}$ Ibid., 280-283.

${ }^{13}$ Ibid., 292.

${ }^{14}$ Ibid., 296. 
rena. No hay evidencia de que haya permanecido en Charo, por lo que es probable que huyera rumbo a la ciudad de México o que después de enero de 1811 se refugiara en Valladolid, controlada por José de la Cruz. En cambio, otro de sus familiares, José Antonio Rosel continuaba apadrinando a niños indígenas del lugar en octubre de ese año. ${ }^{15}$

En cuanto a los indios de la villa, Terán sostiene que éstos secundaron el movimiento por las mismas razones que lo hicieron otros pueblos de indios:

el secuestro de sus bienes y su caja bajo el gobierno económico, el rechazo a la tributación, a las restricciones a la movilidad, a ser considerados como "menores de edad", para acabar con los malos tratos que recibían de los espańoles, la elevada alcabala impuesta a sus productos comerciales y todo lo que los insurgentes trataron de desterrar. ${ }^{16}$

Sin embargo, las evidencias de que disponemos sugieren que los indios de Charo rechazaron la insurrección y se mantuvieron fieles al gobierno español, debido a que en un inicio gran parte de los seguidores de Hidalgo se dedicaban al saqueo, la destrucción y el pillaje, así como a dar muerte a los "gachupines”. Esto quizá explique por qué el gobernador de la república de naturales se preocupara por preservar la "concesión primordial de los terrenos de la villa" que les había otorgado el monarca, aunque no pudieron evitar la quemazón de otros títulos, causada por los rebeldes en el transcurso de 1811, según informó el teniente de Charo al ayuntamiento de Morelia en agosto de $1836 .{ }^{17}$

Por otro lado, muchos indios de Charo desistieron de sumarse a la insurgencia para no perder los "privilegios adicionales" que les había concedido el monarca con respecto a los gobiernos de república en tiempos de las alcaldías. Dicho privilegio consistía en la ayuda

${ }^{15}$ Archivo de la Notaría Parroquial de Charo (ANPCH), Bautismos, lib. 10, años 1809-1834. "Libro en que se asientan las partidas de bautismos de españoles, indios y castas de esta villa de San Miguel Charo y su jurisdicción”, f. 31 r.

${ }^{16}$ Marta Terán, "Gobiernos indígenas en los pueblos michoacanos al final de la Colonia”, en Gobierno y economía en los pueblos indios del México colonial, Colección Científica, coord., Francisco González-Hermosillo Adams, 231 (México: Instituto Nacional de Antropología e Historia, 2001).

${ }^{17}$ AHMM, Actas de cabildo, lib. 147, sesión del 31 de agosto de 1836, f. 129. 
que les brindaba el apoderado o el corregidor de la villa, en todos los asuntos que debían ventilarse ante las autoridades reales; no era lo mismo contar con el respaldo y la asesoría gratuita de un empleado del propio Marquesado, que contratar los servicios de un abogado pagado por ellos, y menos a un fiscal de oficio. ${ }^{18}$

Esto desde luego, no significa que todos los habitantes de Charo y su jurisdicción rechazaran la insurgencia; seguramente hubo gente que se sumó a sus filas y que se pusieron bajo las órdenes de los justicias y administradores de fincas que un año después actuaban en esa zona, particularmente en sitios como Indaparapeo e Irapeo. ${ }^{19}$

En los meses posteriores, diversos cabecillas insurgentes realizaron nuevas incursiones amagando la capital de la intendencia, cuyos ataques debieron contar con la colaboración de algunos habitantes de los pueblos circunvecinos. El primero de ellos ocurrió el 31 de mayo de 1811 y fue encabezado por Luciano Navarrete, Ignacio Rayón, José María Liceaga, Manuel Muñiz, José Toribio Huidobro, Manuel Villalongín y José Guadalupe Salto, entre otros. En esa ocasión los insurgentes no tuvieron éxito, debido al poco alcance de su artillería y a la falta de coordinación en sus movimientos. Algo parecido ocurrió en el ataque del 22 de julio siguiente dirigido por $\mathrm{Mu}$ ñiz, y en el de febrero de 1812 que tuvo lugar en el puerto de Oporo, donde los soldados de Navarrete, Muñiz y José Mariano de la Piedra fueron derrotados por las fuerzas fieles al gobierno español. ${ }^{20}$

\section{Las CORTes CONTRa el SEÑORÍO JURISDiCCIONAL}

Las Cortes españolas se instalaron en la isla de León y comenzaron sus sesiones en el mes de septiembre de 1810. Posteriormente, ya trasladadas a Cádiz, continuaron sus debates. Uno de ellos, plantea-

${ }^{18}$ Terán, "Gobiernos indígenas", 223.

${ }^{19}$ Moisés Guzmán Pérez, La Suprema Junta Nacional Americana y la Independencia. Ejercer la soberanía, representar la nación (México: UMSNH, Gobierno del Estado de Michoacán, Consejo Nacional para la Cultura y las Artes, 2011), 360, 375.

${ }^{20}$ Moisés Guzmán Pérez, El insurgente José Maria Guadalupe Salto. Vida y martirio, Colección Bicentenario de la Independencia, núm. 15 (México: Secretaría de Cultura, Gobierno del Estado de Michoacán, Secretaría de Turismo y Cultura, H. Ayuntamiento de Morelia, Instituto de Investigaciones Históricas, UMSNH, 2012), 79, 93, 98, 101. 
do por el diputado valenciano Antonio Lloret y el secretario de la Cámara, Manuel García Herreros, estuvo orientado a acabar con los señoríos jurisdiccionales, no sólo en España sino también en América. ${ }^{21}$ Como consecuencia, el 6 de agosto de 1811, los diputados aprobaron el decreto número 82 que convertía a los señores en propietarios y otorgaba a favor de la nación espańola los privilegios jurisdiccionales que anteriormente gozaban, como los de impartir justicia y recaudar impuestos. De igual manera, se les dejó de llamar "señor de vasallos"; se les prohibió designar a los síndicos y regidores de los cabildos; y se les convirtió en simples propietarios de bienes muebles e inmuebles. Por consiguiente, los corregidores y alcaldes mayores que estaban a su servicio -sobre todo en América-, cesaron en sus funciones a partir de la publicación del decreto. ${ }^{22}$

Fue hasta finales de octubre de 1811 cuando las autoridades novohispanas conocieron el decreto de las Cortes sobre extinción de señoríos, lo cual generó discrepancias entre las instancias responsables de aplicar dicha orden -la Audiencia, por ejemplo-, y aquellos que defendían los intereses del Marquesado. Mientras algunos oidores sugerían que los jueces privativos del señorío continuaran con sus atribuciones y que los gobernadores de las repúblicas de indios siguieran cobrando las contribuciones por concepto de bienes de comunidad y "medio real de ministros"; los integrantes de la junta de gobierno del Marquesado aceptaban que el "Estado" debía desaparecer y convertirse en propiedad particular, pero se oponían de manera rotunda a dos cosas: a) que los funcionarios fueran nombrados por las autoridades reales; $y \mathrm{~b}$ ) que las rentas señoriales pasaran a formar parte de la Hacienda Pública. ${ }^{23}$

${ }^{21}$ Véase Manuel Chust, La cuestión americana en las Cortes de Cádiz, Biblioteca Historia Social, núm. 2 (Valencia: Centro Francisco Tomás y Valiente unEd Alzira-Valencia, UNAM, 1999), 98-101.

${ }^{22}$ Colección de los decretos y órdenes que han expedido las Cortes Generales y Extraordinarias desde su instalación en 24 de septiembre de 1810 hasta igual fecha de 1811, tomo I (Cádiz: Imprenta Real, 1811), 193-196, http://www.cervantesvirtual.com/obra/coleccion-de-los-decretos-y-ordenes-que-han-expedido-las-cortes-generales-y-extraordinariasdesde-su-instalacion-en-24-de-septiembre-de-1810-hasta-igual-fecha-de-1811--0/ (Fecha de consulta: 29 de junio de 2015).

${ }^{23}$ José Antonio Serrano Ortega, "Las herencias ilustradas y gaditanas en tiempos del 
Por otro lado, mientras los integrantes de la junta proponían que prosiguiese el carácter provisional del gobierno del Marquesado, como ocurría desde antes de la promulgación del decreto del 6 de agosto, otros oidores y fiscales procuraban anular su carácter transitorio con la idea de aplicarlo al pie de la letra. Si no existían más los "vasallos del Marquesado", como insistían los oidores Ambrosio Sagazurrieta, José Ramón Osés y el fiscal Robledo, era lógico que todos los individuos se rigieran por las mismas leyes. En su concepto, el heredero de Cortés era sólo un "propietario particular" por lo que no había razón para mantener vigentes los juzgados privativos; los justicias tendrían que ser nombrados por las autoridades reales, quienes además se ocuparían de atender lo relativo a impuestos, bienes de comunidad y medio real de ministros. ${ }^{24}$ Fue hasta el mes de agosto de 1812 cuando el Real Acuerdo emitió un dictamen definitivo, apoyado en el decreto del 6 de agosto de 1811 que decía:

Han cesado los juzgados privativos y la conservaduría como privilegios concedidos a la casa del marqués del Valle con calidad de señor de vasallos; que también se ha extinguido el gobierno con todas las facultades públicas y jurisdiccionales quedaron en la clase de simple y pura administración particular; que así mismo, se han extinguido todos los demás empleos cuyas funciones son relativas al ejercicio de la jurisdicción que había en la casa. $^{25}$

A esta disposición tendríamos que añadir otro decreto de las Cortes del 7 de octubre de 1812 por el que ordenaba que a los ayuntamientos creados, en los antiguos territorios nobiliarios, les correspondía ejercer la jurisdicción civil y criminal, una medida que minaba fuertemente los privilegios de los seńoríos jurisdiccionales. ${ }^{26}$ En ese sentido, una vez aplicado el decreto del 6 de agosto de 1811

absolutismo Nueva España (1814-1819)", en El sexenio absolutista. Los últimos años insurgentes. Nueva España (1814-1820), coord. José Antonio Serrano Ortega, 217-218 (Zamora: El Colegio de Michoacán, 2014).

${ }^{24}$ Ibid., 218.

${ }^{25}$ Idem.

${ }^{26}$ Ibid., 219. Además: Concepción de Castro, La revolución liberal y los municipios españoles (Madrid: Alianza Editorial, 1979), 43-56. 
que igualaba la condición de Charo con los demás pueblos de la intendencia, los vecinos podían establecer legítimamente su propio ayuntamiento constitucional, y retirar éste "todos los signos de vasallaje que haya en sus entradas, casas capitulares o cualesquiera otros sitios", como disponía el decreto del 26 de mayo de $1813,{ }^{27}$ pero no hay evidencia de que esto haya sucedido en la villa, tanto por el estado de guerra que impedía la realización de elecciones, como por el retorno de Fernando VII al trono de Espańa y el restablecimiento de la monarquía absoluta.

\section{Los efectos de la GUerRa insurgente en Charo}

Como era de esperarse, la revolución trajo como consecuencia una continua migración de gente que huía del acoso insurgente o que buscaba un sitio más seguro para subsistir. Decenas de personas y familias enteras que vivían en el medio rural, se trasladaron a los centros urbanos más cercanos donde podían obtener alimentos y, sobre todo, seguridad a sus personas. Es el caso de Juan Nepomuceno Cuevas, que aunque originario de Tlalpujahua, desde niño vivió en la villa de Charo hasta la edad de 13 años que se fue a Valladolid y donde radicó por tiempo de seis años haciendo estudios; después estuvo un año en el pueblo de Tuzantla, otro año más en la villa de Zitácuaro, de ahí regresó a la villa de Charo, luego estuvo por segunda vez tres años en este sitio y para 1813 radicaba definitivamente en Valladolid por causa de la guerra. ${ }^{28}$

En algunos lugares cercanos a Charo, como la hacienda de Irapeo, se creó una "tropa de guarnición" con gente joven de las rancherías y lugares aledańos como La Cantera y Zurumbeneo. Su tarea consistía en contener las incursiones de las gavillas rebeldes que asolaban la zona, particularmente las de los insurgentes de la

${ }^{27}$ Colección de los decretos y órdenes de las Cortes de España que se reputan vigentes en la República de los Estados Unidos Mexicanos, edición facsimilar de la de 1829, estudio introductorio de Óscar Cruz Barney (México: Suprema Corte de Justicia de la Nación, 2005), 79.

${ }^{28}$ AHCM, Parroquial, sacramental, matrimonios, información matrimonial, año 1813, caja 966, carpeta 218. Información matrimonial de Juan Nepomuceno Cuevas y María Ignacia Gutiérrez Busto, Valladolid, 8-13 de enero de 1813. 
localidad conocida como Zacate Colorado, perteneciente al curato de Copuyo, quienes no sólo se dedicaban a infundir temor a los indios, labradores y arrieros que se habían mostrado contrarios a la Independencia, sino también al rapto de mujeres jóvenes, quienes sólo en contadas ocasiones lograban ser liberadas, gracias a una promesa de matrimonio que les habían dado. ${ }^{29}$

En medio de estos problemas, surgieron otros a principios de 1814 entre el cura José Mariano de la Parra y los indios de la villa, porque estos últimos exigían que se les quitara la tasación y se les impusiera el arancel general del obispado. Parra se había hecho cargo de aquel curato desde mediados de $1800 \mathrm{y}$ en catorce ańos que tenía de ejercer su ministerio no había tenido la más mínima queja por parte de los naturales, por lo que pensaba que los tiempos de revolución eran la causa de que "muchísimos hombres" hubieran cambiado tanto, "en lo político y moral". ${ }^{30}$

A pesar de la guerra y de la negativa de los indígenas a solventar los gastos y necesidades de la Iglesia, el curato no había dejado de estar asistido por el sacerdote del lugar, porque a pesar de lo "reducido" de su feligresía y no necesitar de más clérigos, la doctrina llegó a contar con el auxilio de fray José Rodríguez, un religioso jubilado de la orden de San Diego. Cuando el cura Parra enfermó y se retiró unos días a Valladolid para aliviarse, el padre Rodríguez quedó al frente del curato; en el ínterin, los indígenas elevaron una queja al gobierno de la diócesis, acusándole que por omisión habían fallecido varias personas sin recibir los sacramentos, cuando en realidad, se averiguó que fueron ellos los que en una ocasión no habían acudido al confesor por falta de cabalgadura y, en otra, le encontraron celebrando misa, y aun así el padre dieguino otorgó la extremaunción. ${ }^{31}$

${ }^{29}$ AHCM, Parroquial, sacramental, matrimonios, información matrimonial, año 1813, caja 966, carpeta 219. Información matrimonial de José Joaquín Paz y María Guadalupe Viera, ante el bachiller José Mariano de la Parra, cura propietario de ese partido. Villa de Charo, 17 de abril de 1813.

${ }^{30}$ AHCM, Diocesano, justicia, procesos legales, pagos, 1801-1899, caja 745, carpeta 13. "Expediente promovido por los naturales de la villa de Charo sobre que se le quite la tasación y establezca en aquel curato el arancel general del obispado". Valladolid, 22 de mayo de 1814 .

${ }^{31}$ Idem. 
Otra queja estaba dirigida contra el cura Parra. Los indígenas argumentaban que les exigía el pago de las pindecuas "con rigor e inmoderadamente", pero esto era sólo una estrategia para no pagarle las cantidades de dinero que desde el año de 1811 debían el mayordomo del hospital y los regidores del cabildo. Por otro lado, tampoco entregaban el pescado, mantas y otros productos seńalados en el pindecuario; ${ }^{32}$ le retiraron sus "escasas asistencias y contribuciones”, y cuando viajó a Valladolid, apenas logró que le pagaran un casamiento conforme al pindecuario, pero nada por los más de doce entierros que había oficiado. ${ }^{33}$

Como decíamos, el argumento de los indígenas de Charo para no pagar era que querían ceńirse al arancel del obispado, pero cuando el cura Parra trató de hacerlo efectivo en los términos suscritos por el escribano de república, tampoco se dio el pago, alegando no tener dinero. Parra explicó al gobierno diocesano que el argumento de los indios era falso, ya que tenía pruebas contundentes de

ser ellos, los únicos de los pueblos circunvecinos, quienes más fácil y seguramente frecuentan este y otros lugares, vendiendo sus efectos a los subidos precios que no lograban antes y que tienen proporciones para comerciar, porque casi los más son dueños de animales y siembran cincuenta fanegas y siete de trigo, como cincuenta fanegas de maíz, fuera de lo que por separado cultivan para el hospital, en tierras que le están designadas con algún mueble, destinado todo esto para pagar el párroco, sin necesidad de pensionar al pueblo.

También los regidores siembran dos cargas de trigo para la contribución del peso mensual que cada uno da al cura; de suerte que satisfechas las limosnas de misas, y otros menudos gastos, le queda el sobrante que consumen en tiendas domésticas y en aquellos que quieren: por lo que en consecuencia, son totalmente inciertas las necesidades que tanto aparentaron con el fin de que las pindecuas les fuesen rebajadas; las que acaso podrán reducir para no pagar ahora conforme el arancel, parece no llevan

${ }^{32}$ Libro donde se asentaban las pindecuas que daban los indios.

${ }^{33}$ AHCM, Diocesano, justicia, procesos legales, pagos, 1801-1899, caja 745, carpeta 13. "Expediente promovido...", Valladolid, 22 de mayo de 1814. 
otras miras, sino las de que el párroco les sirva de balde, con todo de saber que son cortísimos los emolumentos que producen los ranchos. ${ }^{34}$

Ante esta situación, el obispo electo Manuel Abad y Queipo expidió un decreto de fecha 5 de mayo de 1814 ordenando que los indios de Charo sostuvieran al párroco y pagaran sus derechos parroquiales con arreglo al arancel, tal como lo hacían "los individuos de las demás clases" y de acuerdo con lo resuelto "por el augusto congreso de las Cortes en el artículo $3^{\circ}$ del soberano decreto de 9 de noviembre de mil ochocientos doce". ${ }^{35}$ Parra propuso que, para hacer que los indios de Charo cumplieran con sus obligaciones y le pagaran sus adeudos, era necesario que la república o los naturales que la conformaban quedasen como responsables

a la satisfacción de los derechos que causen aquellos que sin justo motivo o con pretextos frívolos se excusen de enterarlos, pues los indios saben mucho mejor que el cura, los que dentro de ellos se hallan insolventes; y siendo responsables cuidarán de que correspondan con puntualidad los que de otra suerte no lo ejecutarían, y los republicanos, no les serían padrinos o protectores de sus excusaciones las más veces injustas: cuya solicitud, tanto más se presenta arreglada, cuanto en poder de ellos podrían quedar los animales y tierras de sembrar, que como he dicho se hallan consignadas para el divino culto; y con el residuo o aquello que gastan en sus fiestas, será fácil se reintegren de lo que paguen por algunos de dichos naturales. ${ }^{36}$

El cura Parra también sugería que las obligaciones se extendieran a lo que antes se consideraba "los derechos de fábrica" (reparación de iglesia, servicio de sacristán, campaneros y asistencia al cura), porque como habían quedado exentos del servicio personal, era necesario que pagaran los servicios que importaba la reparación de la iglesia, compra de vino, aceite y cera, y que no estaba contemplado en el arancel ni el cura tenía por que solventarlo. Insistía en que los

\footnotetext{
${ }^{34}$ Idem.

${ }^{35}$ Idem.

${ }^{36} \mathrm{Idem}$.
} 
indios le pagaran según el arancel todo lo adeudado desde el día en que lo admitieron, que fue el 8 de mayo de $1814 .{ }^{37}$

Enseguida, Parra dirigió sus críticas a los regidores indios del ayuntamiento que alegaban no tener dinero. Según el cura, cada uno de ellos era dueńo de "una mulita" que le alquilaban a un real por cabeza y otro real más que debía pagar al mozo o arriero que la conducía. Era obvio que debieron existir otras personas que necesitaban de este servicio, por lo que era infundado su argumento "de que en ocasiones ponen dinero de sus bolsas", cuando dos reales eran suficientes para su manutención. ${ }^{38}$

Su hermana tampoco escapó de los ataques e injurias de que fue objeto, sólo porque obedeció las indicaciones de Parra, al impedir que las muchachas que iban a ayudarle salieran por la noche y en vez de irse a sus casas "se pusieran a retozar con los muchachos de doctrina”. Tanto el vicario, como el cura Parra y su hermana fueron presionados por los indios para que se fueran a vivir a otra parte. Parra decía que para evitar dificultades debía establecerse el cobro del arancel, porque ni su hermana los volvería a mandar ni él los volvería a ocupar (si no es pagándoles) "en que cuiden ovejas y hagan otras cosas que incluyen en sus guerras". ${ }^{39}$

Dos días después, el 24 de mayo, el gobierno diocesano resolvió que los indios de Charo debían de cubrir los derechos parroquiales conforme al arancel y no por tasación, y que la república o principales que la componían quedaran como responsables de cobrar los derechos de parroquia y fábrica a los indios "que con pretextos frívolos" se negaran a pagarlos. ${ }^{40}$

De este modo, los indios se sujetaron al arancel, pero exigieron el reparto de unas tierras para siembra de trigo que según ellos les pertenecían. Sin embargo, el cura acordó con el corregidor darlas en arrendamiento a los indios para sufragar los gastos del culto; en realidad, las tierras de los Corrales pertenecían al curato de Charo por haberlas dejado sus dueños al párroco, con la obligación de decir

\footnotetext{
${ }^{37}$ Idem.

${ }^{38}$ Idem.

${ }^{39}$ Ibid., f. 4.

${ }^{40}$ Ibid., f. 5.
} 
varias misas al año por el descanso de su alma y fue producto de una transacción que tuvo la mitra con los religiosos de San Agustín. ${ }^{41}$

Meses después, el gobernador Marcos Felipe junto con el común y naturales de Charo, apoyados por el "escribano interino" José de Jesús, se quejaron ante el intendente Merino de abuso de autoridad y malos tratos por parte del corregidor Rosel, así como del embargo de varias cargas de trigo que les había hecho el cura Parra, quedándose con una huerta. No se conoce la respuesta de Rosel, pero sí la del cura Parra quien afirmó categórico que el corregidor

los trata bien, en nada los pensiona y sólo les exige aquellos derechos que les da el arancel o la inveterada costumbre. Los indios de esta población no tienen tierras propias o de modo que sean hereditarias y transmisibles por derecho de sangre a sus hijos, nietos y parientes; y el estilo ha sido que muriendo entre ellos la cabeza de alguna familia, ocurren los de esta misma $u$ otros a que se les apliquen la tierras que el difunto poseía y el juez las reparte y percibe un peso por dar la posesión, mediando entre ellos y cuidando de que queden contentos. ${ }^{42}$

Lo que era un hecho es que cada vez que tenía oportunidad, el corregidor Rosel apoyaba con cuanto podía a las tropas del rey cuando acudían a la villa a pedir auxilio. Así ocurrió en septiembre de 1814 cuando un convoy de soldados entró en la población; el corregidor "vino de sus sembrados", le facilitó al oficial doce arrieros que necesitaba, entre ellos dos presos "por cosas ligeras", y le consiguió algunas mulas que los propios soldados corrieron a juntar en un paraje. Así mismo, junto con el cura Parra trataba de contener los continuos "festines y embriagueces" de los indios, en los que éstos invertían casi todo su dinero, olvidándose de sus obligaciones para con el cura y la propia Iglesia. Era el juez privativo quien se encargaba de las reparaciones del inmueble, del retablo que costeó un señor de apellido Peña, así como del entarimado que había hecho el común de naturales de la misma jurisdicción. También pro-

${ }^{41}$ AHMM, fondo Independiente, Siglo XIX I, libreta 11, caja 10, exp. 22, Valladolid, año 1815. José Mariano de la Parra a Merino, Charo, 29-XII-1814.

${ }^{42}$ Idem. 
veía de suficiente cera para el altar mayor, sitio donde se realizaban las misas de renovación los jueves del año y en las demás misas cantadas. $^{43}$

En medio de estos problemas cotidianos, el incremento de la violencia causada por la guerra siguió preocupando a los habitantes de la villa de Charo. Aunque los realistas lograron batir a Morelos en Valladolid y poco después en Puruarán (diciembre de 1813 y enero de 1814, respectivamente), ni las operaciones militares salidas de la división de José Antonio Andrade acantonada en Valladolid, ni las ejecutadas por Ciriaco de Llano en el cerro de Cóporo, cercano a Jungapeo, habían logrado pacificar la provincia. Por el contrario, continuó el acoso insurgente a la capital de la intendencia.

A principios de diciembre de 1814, los rebeldes intentaron incendiar la hacienda del Rincón, bastante inmediata a la ciudad, pero al no conseguirlo quemaron la de La Goleta ubicada a 3 leguas de Valladolid. De igual modo, el primero de enero de 1815, incendiaron los pueblos y parroquias de los alrededores de Valladolid entre los que se encontraban Santa María, Undameo, Tiripetío y Tacícuaro así como diferentes haciendas y ranchos que rodeaban aquella capital. Lo más grave de todo era que otras poblaciones ubicadas en un radio de 10 leguas a la redonda, con las que mantenía una estrecha comunicación, como Zinapécuaro, Indaparapeo, Charo, Atécuaro, Jesús y San Miguel del Monte, las haciendas de Quirio, Zacapendo, Los Naranjos, San Bartolo, Queréndaro y otras más, habían sido amenazadas con padecer el mismo castigo. Decía Merino que "no sólo han hecho esta amenaza de palabra repetidas veces, sino que han publicado tan bárbaro mandado por orden de la Junta, fijando bandos y edictos en los pueblos que dominan”. ${ }^{44}$

Merino mencionaba a Calleja que, en distintas partes de su provincia, los habitantes continuaban emigrando diariamente a otros lugares más seguros, obligados por la miseria, la escasez de víveres y lo caro que se vendían los artículos de primera necesidad. ${ }^{45}$

${ }^{43}$ Idem.

${ }^{44}$ AGN, Operaciones de Guerra, vol. 583, exp. 8, f. 150. Manuel Merino al virrey Calleja, Valladolid, 9 de enero de 1815.

${ }^{45}$ Idem. 
La guerra afectó de manera significativa a la villa de Charo. Antes de 1810, la contaduría general de la casa del Estado y Marquesado del Valle percibía anualmente por concepto de rentas un total de 1,529 pesos. De esa cantidad, 1,310 pesos provenían del arrendamiento de ranchos; 73 pesos los daban los habitantes de Tzitzio; $y$ 146 pesos más eran entregados por los vecinos de Patámbaro. De este dinero sólo se utilizaban 150 pesos para pagar al maestro de escuela de primeras letras que tenía asignado. Después de la Independencia las rentas se habían reducido a tan sólo 223 pesos al año, es decir, alrededor de $14.6 \% .^{46}$

Del mismo modo, la guerra repercutió en la vida económica del pueblo de indios. Lejarza señala que con el conflicto "el vecindario de Charo perdió aún mucho más [pues] los indios poseían en los últimos años 2,500 reses de cría; 200 yuntas, 900 yeguas, $300 \mathrm{mu}$ las, 200 asnos y 2,000 cabezas de ganado menor", pero cuando terminó la guerra sus bienes se hallaban muy reducidos. ${ }^{47}$ En cuanto a la situación de sus vecinos, el teniente de marina R. W. H. Hardy, un viajero inglés que visitó Valladolid algunos años después, señaló que "Charo, igual que Lerma [...] no tienen más que 20 miserables chozas; sus moradores manifiestan gran pobreza y no se muestran orgullosos de la distinción hecha a sus respectivas ciudades". ${ }^{48}$

\section{EN EL SEXENIO ABSOLUTISTA}

El Tratado de Valençay firmado en la localidad francesa del mismo nombre, el 11 de diciembre de 1813, entre José Miguel de Carvajal, duque de San Carlos, y Antoine René Mathurin, conde de Laforest, fue un acuerdo por el que Napoleón Bonaparte aceptaba la suspensión de las hostilidades entre Francia y España, reconocía como rey a Fernando VII y a los territorios que antes de 1808 estaban bajo

${ }^{46}$ Juan José Martínez de Lejarza, Análisis estadístico de la provincia de Mechuacan en 1822, reedición correspondiente a la primera de 1824 (Morelia: Fimax Publicistas, 1974), 39.

${ }^{47}$ Idem.

${ }^{48}$ R. W. H. Hardy, Viajes por el interior de México en 1825, 1826, 1827 y 1828, Colección Linterna Mágica, núm. 23, presentación de Ernesto de la Torre Villar (México: Editorial Trillas, 1997), 66. 
soberanía de la familia real española. Esto fue consecuencia de las derrotas sufridas en la Guerra de Independencia y el progresivo deterioro de las tropas francesas causadas por las guerrillas.

El 12 de abril de 1814 en Valencia, 69 diputados de tendencia ultraconservadora le presentaron a Fernando VII un documento conocido como Manifiesto de los persas, en el que renegaban de las medidas liberales de las Cortes y le propusieron el retorno a la monarquía absoluta. Con ese apoyo, el 4 de mayo el soberano decretó la abolición de la Constitución Politica de la Monarquía Española y todos los decretos sancionados por las Cortes. ${ }^{49} \mathrm{El} 24$ de ese mismo mes, el Supremo Ministerio de Gobernación de Ultramar le envió a Calleja una real orden en la que le informaba que, además de declarar nula y sin ningún valor la Constitución de Cádiz, el rey

se ha servido resolver, que cesen por ahora las Diputaciones Provinciales que se habían creado en las Provincias de las dos Américas y de las del Asia, custodiándose por los Gobernadores de ellas todos los expedientes y papeles que puedan pertenecerlas, y que las facultades que ejercían en virtud de su reglamento y respectivos Decretos corran en lo sucesivo, hasta tanto se establezca lo que convenga a cargo de las mismas autoridades y corporaciones que las desempeñaban antes de publicarse la referida Constitución. ${ }^{50}$

Posteriormente, el virrey Calleja expidió el bando del 20 de julio de 1815 , en el que dio a conocer una real cédula del 28 de diciembre de 1814, que ordenaba el cese de todos los ayuntamientos constitucionales de las dos Américas e Islas Filipinas, reestableciéndose los alcaldes ordinarios, regidores y demás capitulares que antes estaban. Asimismo, en los sitios donde se crearon ayuntamientos en virtud de la Carta de Cádiz, como en Valladolid de Michoacán, ${ }^{51}$ se

${ }^{49}$ Isabel Enciso Alonso-Muñumer, Las Cortes de Cádiz, Historia del mundo para jóvenes/serie: Historia de Espańa (Madrid: Ediciones Akal, 1999), 44 y ss.

${ }^{50}$ Centro de Estudios de Historia de México-Carso (CEHM-Carso), fondo CDxxxvi. Bandos de Félix María Calleja, 1814-1816, carpeta 1/48, exp. 14. Impreso.

${ }^{51}$ Carlos Juárez Nieto, El proceso político de la independencia en Valladolid de Michoacán, 1808-1821 (Morelia: Secretaría de Difusión Cultural y Extensión Universitaria, Instituto de Investigaciones Históricas, Universidad Michoacana de San Nicolás de Hidalgo, Centro Regional Michoacán del INAH, 2008), 97-100. 
suspendieron absolutamente por afectar a la Real Hacienda ya que se consideraban oficios vendibles y renunciables. De igual manera, cesaron los jueces de primera instancia en sus funciones, siendo retomadas por los intendentes, subdelegados y alcaldes mayores como lo mandaban las Ordenanzas, y las audiencias volvieron a ejercer su jurisdicción y funciones que antes tenían. ${ }^{52}$ El propio Calleja se encargó de difundir, el 22 de julio, otra real cédula del rey el primero de septiembre de 1814, que prohibía "fijar cartel alguno, distribuir ningún anuncio, ni imprimir diario escrito, ni obra alguna de cualquiera clase que sea, sin que preceda su presentación a la persona a cuyo cargo se halle el gobierno político y militar, quien dará o negará el permiso para la impresión o publicación". ${ }^{53}$

Entre los años de 1814 y 1815, hubo un nuevo embargo de Charo por parte de la Corona y los descendientes de los marqueses del Valle perdieron el privilegio de designar a los corregidores de la villa. ${ }^{54}$ A finales de 1814, los representantes legales del duque de Terranova pidieron al monarca la liberación de sus bienes por considerarlo injusto, de cuyas resultas Fernando VII tuvo a bien tratar este asunto con su Consejo. Tanto los informes dados por éste como por la indagatoria que de orden del Consejo de Nápoles hizo su encargado de negocios en Espańa al secretario de Estado, Pedro Cevallos, se consideró favorable a dicho duque porque no obstante haber sido natural, domiciliado y vasallo del rey de Nápoles

fue nombrado y pasó a París de tal embajador por José Bonaparte a principios de mil ochocientos ocho, tiempo en que era éste el soberano reconocido, que se hallaba en plena paz con Espańa y está en paz y armonía con la Francia, luego que Bonaparte manifestó sus ideas hostiles en contra del rey.

Lo que llevó al "Deseado" a ordenar la restitución de sus bienes al duque de Terranova fue el hecho de que su tío, Fernando IV rey

52 CEHM-Carso, fondo I. Un Cedulario de la Nueva Galicia, marzo de 1791-diciembre de 1816, carpeta 9/9. exp. 404 .

${ }^{53}$ CEHM-Carso, fondo CDXXXvi. Bandos de Félix María Calleja, 1814-1816, carpeta 1/48, exp. 87. Impreso.

${ }^{54}$ Gerhard, Geografía histórica, 109. 
legítimo de Nápoles, había restituido a los españoles el goce de sus propiedades que allí les habían secuestrado. Con base en ello, el primero de agosto de 1816, el soberano de España decretó que se pusiera en posesión de sus bienes al duque de Terranova o de sus legítimos sucesores y cinco días después se tomó razón del decreto en la Contaduría General de la América Septentrional.

Habiéndose resuelto el asunto en la metrópoli, el fiscal de Real Hacienda procedió a dar cumplimiento a la orden de entrega al oidor Manuel Bataller "como encargado del gobierno económico y directivo de la Casa, y no como juez privativo de dicho Estado, por estar extinguidos los señoríos jurisdiccionales". ${ }^{55}$

Posteriormente se libró orden a los subdelegados de Toluca, Coyoacán y Cuernavaca para que en la misma forma entregaran las casas en sus territorios pertenecientes al marqués del Valle, y oficio a los intendentes de Oaxaca, Valladolid y Veracruz para que dieran igual orden a los subdelegados de Cuatro Villas, Xalapa de Tehuantepec, Tuxtla y Charo, y que de ahora en adelante todos se entendieran con el referido juez Bataller. Finalmente, el oidor recibió la casa y los libros de cuentas pertenecientes al Marquesado, de lo cual se dio por satisfecho.

La aplicación de los decretos de las Cortes, y la jura de la propia Constitución liberal en la provincia de Michoacán, fue una tarea bastante complicada debido al estado de guerra que se vivía, pudiendo decirse que únicamente en Valladolid logró cumplirse el mandato de las Cortes, y eso con cierta reticencia por parte del intendente Merino. ${ }^{56}$ Con el regreso del absolutismo parecía que las cosas volvían al estado en que se encontraban en 1808, pero no fue así. Serrano Ortega ha demostrado que a pesar de que se disolvieron los ayuntamientos constitucionales creados en los antiguos señoríos, los alcaldes mayores y los regidores fueron nombrados por el monarca, no por el señor, y los alcaldes y regidores de los cabildos serían confirmados por las cancillerías y las Audiencias. Por otro lado, el rey suprimió el privilegio señorial de nombrar a los encargados de

${ }^{55}$ AGN, Hospital de Jesús, vol. 427, leg. 244 (1), exp. 34. El virrey Apodaca a Miguel Bataller, México, 21 de noviembre de 1816.

${ }^{56}$ Juárez, El proceso político, 92, 145 y ss. 
impartir justicia a sus vasallos y, posteriormente, con su real orden del 15 de septiembre de 1814, derogó parcialmente el privilegio que tenían los seńores de recaudar y usufructuar impuestos y rentas que no pertenecían a sus dominios territoriales. ${ }^{57}$

En el caso de Charo, Rosel volvió a hacerse cargo de su empleo y restableció el antiguo cabildo indígena en la villa. Una de las tareas a las que debió avocarse el corregidor fue a la elaboración de un censo sobre el número de habitantes que había en la jurisdicción, de acuerdo con la orden que giró el intendente Merino a todos los subdelegados de la intendencia o empleados que se ocuparan de la impartición de justicia. Esta medida, que fue implementada por las Cortes de Cádiz desde 1812 y que el estado de guerra en Nueva España había impedido realizarla, fue retomada por el monarca a través de su real resolución del 29 de noviembre de 1817, por la que ordenó "formar la Estadística general de este reino". ${ }^{58}$

La información que remitiría Rosel debía contemplar el "número y clase de habitantes de los pueblos, haciendas y ranchos de esa jurisdicción”, a partir de un censo o padrón que el corregidor debía mandar hacer sin dilación alguna. Ya terminado, debía enviar dos tantos al intendente; uno que sería remitido al virrey Apodaca y el otro que se guardaría en el archivo de la intendencia. La misma indicación se les dio a los subdelegados de Zitácuaro, Tlalpujahua, Zinapécuaro, Uruapan, Apatzingán, La Piedad, Los Reyes, Purépero, Huetamo, Jiquilpan y Zamora. ${ }^{59}$

Es probable que Rosel no estuviera a gusto en su corregimiento, debido a los cortos beneficios que recibía y que se habían reducido drásticamente por causa de la guerra. Lo cierto es que un año antes de que entrara nuevamente en vigor la Constitución de Cádiz en la Nueva España, el 20 de julio de 1819, dirigió un escrito a Manuel de Hisca, administrador de la Casa del Estado, pidiéndole que "tuviese la bondad de nombrar un sujeto para que se encargase de las rentas

${ }^{57}$ Serrano, "Las herencias ilustradas", 219-220.

${ }^{58}$ AHCM, Diocesano, gobierno, correspondencia, autoridades civiles, 1814-1819, caja 33, carpeta 33. Merino a los subdelegados y corregidor de la intendencia, Valladolid, $1^{\circ}$ de diciembre de 1818 .

${ }^{59}$ Idem. 
de esta jurisdicción"; y con esa misma fecha escribió otra carta al intendente Merino diciéndole que nombrara como subdelegado de Charo a otra persona, porque él no estaba interesado en el empleo. ${ }^{60}$

\section{La SUPRESión DEL CORREgimiento de Charo}

El rey juró la Constitución el 9 de marzo de 1820 y en cuestión de meses se hizo lo propio en las distintas posesiones de la Monarquía española. Por segunda ocasión se promovió la creación de ayuntamientos constitucionales en aquellas poblaciones que reunieran el requisito de los mil habitantes o que por su lejanía con respecto a la cabecera carecieran de una buena administración de justicia. Así mismo, se crearon varias Diputaciones Provinciales para el gobierno interior de las provincias, entre las cuales estaría la de Valladolid de Michoacán en 1822, que se había separado de la Diputación Provincial de Nueva España.

La instalación del ayuntamiento constitucional en la villa de Charo fue una de las más tempranas que se dieron en Valladolid, ya que tuvo lugar el 27 de octubre de 1820, apenas unos dos o tres meses después del que se estableció en la capital de la intendencia homónima. La creación del ayuntamiento se realizó de acuerdo con lo estipulado en algunos artículos de la Constitución Política de la Monarquía Española promulgada en Cádiz el 19 de marzo de 1812 y en cumplimiento de los artículos $4^{\circ}, 6^{\circ}, 7^{\circ}$ y $8^{\circ}$ del decreto de las Cortes de 23 de mayo del mismo año, que contenía el reglamento que se debía observar. ${ }^{61}$

$\mathrm{Al}$ corregidor no le quedó otra opción que acatar lo dispuesto en aquel decreto. Desde el 22 de octubre se dedicó a girar varios oficios a los sujetos nombrados para formar dicho ayuntamiento y llegado el día 27, entre las 10 y las 11 de la mañana se presentaron frente a él dichos señores para tomarles el juramento que mandaba el artículo 337 de dicha Constitución, tomando posesión de sus respectivos car-

${ }^{60}$ AHCM, Diocesano, gobierno, correspondencia, autoridades civiles, 1820-1827, caja 34, carpeta 43. Antonio Abad Rosel al intendente Merino, Charo, 1 de diciembre de 1820 .

${ }^{61}$ AGN, Indiferente virreinal, Ayuntamientos, caja 3069, exp. 042, ańo 1820, 5 fs. 
gos: de alcalde, don Anastasio Carretilla "natural de esta villa”; primer regidor, don Domingo Rojas; segundo regidor, don Pedro Benzes; tercer regidor, don Pablo Galindo; cuarto regidor, don Ildefonso Piñón, natural; y don Atilano Iriarte, también natural, desempeñaría las funciones de procurador síndico.

Ya instalado el ayuntamiento en el mismo edificio que ocupaba el corregidor, ${ }^{62}$ nombraron por secretario a Francisco Redondo y para depositario de los caudales de propios y arbitrios que habrían de colectarse a Antonio Amaya, ambos vecinos de Charo. Tres días más tarde, Rosel en su carácter de corregidor y juez político de la villa "que es del Marquesado del Valle y su partido", junto con el secretario designado por la corporación, certificaron la creación de la corporación.

Como era costumbre, el todavía corregidor informó al intendente Merino los pormenores de la instalación y le remitió el documento certificado que hablaba de su composición. Merino a su vez, desde su oficina en Valladolid, remitió una certificación triplicada al virrey Juan Ruiz de Apodaca comunicándole la creación del ayuntamiento constitucional el 6 de noviembre de $1820 .{ }^{63}$

Dos semanas después, el 20 de noviembre, Merino envió un oficio a Rosel notificándole estar suprimido el corregimiento de Charo que tenía a su cargo, en virtud de lo que prevenía el artículo $3^{\circ}$, capítulo 2 del decreto de las Cortes sobre arreglo de tribunales. Bernardo García señala que "cuando el señorío desapareció y con él, naturalmente, la forma de dominio que le era propia, solo quedaron a los marqueses del Valle esas propiedades que por particulares títulos eran suyas, del mismo modo que cada particular o cada comunidad conservaron las propias", y la casa donde atendía Rosel fue una de ellas, la cual todavía en 1835 formaba parte de sus bienes. ${ }^{64}$

${ }^{62}$ Bernardo García Martínez, El Marquesado del Valle. Tres siglos de régimen señorial en Nueva España, Colección Nueva Serie, núm. 5 (México: El Colegio de México, 1969), 87.

${ }^{63}$ AHCM, Diocesano, gobierno, correspondencia, autoridades civiles, 1820-1827, caja 34, carpeta 43. Antonio Abad Rosel al intendente Merino, Charo, 1 de diciembre de 1820.

${ }^{64}$ García, El Marquesado del Valle, 87, 89. 
Para prevenir los daños que pudiera sufrir el Marquesado del Valle en las rentas que como corregidor había cobrado, Merino le autorizaba a fungir como subdelegado interino a fin de que continuara ejerciendo en Charo dichas funciones "como si lo hubiese sido, ceñidas a lo que prescribe el citado decreto sobre arreglo de tribunales". ${ }^{65}$ La oferta del intendente induce a pensar que Rosel ejercía una autoridad plena y reconocida en aquella villa, que tendría injerencia en los asuntos tratados por el ayuntamiento constitucional de Charo, $\mathrm{y}$ que se ocuparía de atender los problemas que se presentaran en otras partes de su jurisdicción donde no hubiese ayuntamiento.

Pero don Antonio volvió a recordarle su escrito de julio del año anterior en el que rechazaba el ofrecimiento; inclusive giró cinco oficios sobre el particular sin obtener respuesta del intendente. Era claro que para Merino lo más importante era contar con una persona de la capacidad y experiencia de Rosel, para que se ocupara de los asuntos de aquella subdelegación. Sería hasta el primero de diciembre de 1820 cuando Rosel le comunicó a Merino que ese día renunciaba formalmente "por lo respectivo a la administración de justicia", y terminaba su escrito diciendo:

Siéndome gravoso seguir más tiempo en este miserable lugar, suplico a vuestra señoría se digne su bondad dar por admitida esta mi renuncia y si lo tuviese a bien hacérsela presente al señor gobernador de la mencionada Casa del Estado para que su señoría determine lo que sea de su superior agrado. Charo, diciembre $1^{\circ}$ de 1820 . Antonio Abad Rosel. [Rúbrica]. ${ }^{66}$

La vida de Rosel es poco visible en la documentación después de que presentara su renuncia, de hecho no sabemos a ciencia cierta si se la aceptaron. Es probable que continuara viviendo en la villa de Charo después de consumada la independencia, pues, el $12 \mathrm{de} \mathrm{di-}$ ciembre de 1821 asistió como elector por el partido de Charo a la reunión de electores que tuvo lugar en Valladolid, y de la cual saldría

${ }^{65}$ AHCM, Diocesano, gobierno, correspondencia, autoridades civiles, 1820-1827, caja 34, carpeta 43. Antonio Abad Rosel al intendente Merino, Charo, 1 de diciembre de 1820 .

${ }^{66}$ Idem. 
nombrado el diputado que representara a la provincia en la "Excelentísima Diputación Provincial de México", tal como lo estipulaba el artículo 328 de la Constitución Politica de la Monarquía, y cuya elección no llegó a realizarse por las maniobras del ayuntamiento de Valladolid, argumentando que no se tenía la orden expresa del ministerio de Ultramar. ${ }^{67}$

\section{Charo y la Diputación Provincial}

Como habíamos señalado anteriormente, además del ayuntamiento constitucional, la Diputación Provincial fue otra de las instituciones fundamentales creada por decreto de las Cortes de Cádiz. Su importancia radica en el hecho de que estas instancias se encargaron no sólo de administrar el gobierno interior de sus respectivas provincias, sino que con el correr de los años serían la cimiente del federalismo en México, una tesis demostrada desde hace tiempo por la doctora Nettie Lee Benson. ${ }^{68}$

Si los asuntos relativos al gobierno local eran de por sí importantes, no lo eran menos aquellos relacionados con los territorios adjudicados a un señorío jurisdiccional. Es por eso que en su sesión del 22 de diciembre de 1820, la Diputación Provincial de México ordenó que se formara un plan o estado de los propios y arbitrios así como de los bienes de comunidad de las ciudades, villas, lugares y pueblos del territorio del Estado y Marquesado del Valle, en el que se precisaran los gastos anuales y sobrantes de cada lugar. El virrey Juan Ruiz de Apodaca fue el encargado de girar la orden al administrador general de dicho Estado, el 8 de enero de 1821, desde la ciudad de México. ${ }^{69}$

Para el administrador fue difícil cumplir el mandato del virrey porque jamás habían ingresado en su tesorería los productos de di-

${ }^{67}$ Actas y decretos de la Diputación Provincial 1822-1823, estudio introductorio de Xavier Tavera Alfaro (Morelia: H. Congreso del Estado de Michoacán, 1989), p. 11 del estudio.

${ }^{68}$ Nettie Lee Benson, La diputación provincial y el federalismo mexicano, Serie Estudios Parlamentarios, núm. 1 (México: Cámara de Diputados li Legislatura, 1980).

${ }^{69}$ AGN, Hospital de Jesús, vol. 427, leg. 244 (1), exp. 27. "Ańo de 1821. La excelentísima Diputación Provincial sobre que se formó un plano o estado de propios y arbitrios y bienes de comunidad de la jurisdicción del Estado y Marquesado del Valle”. 
chos ramos y por lo tanto, no podía proceder a formar el plan o estado que solicitaba la Diputación. Tampoco pudo hacerlo en cuanto al ramo de bienes de comunidad "porque siendo los gastos tan eventuales que ni por un cálculo prudente pueden determinarse, menos se puede por consiguiente deducir sus sobrantes". No obstante se comprometió a formar una lista de los productos anuales que se habían entregado en su oficina pertenecientes a los bienes de comunidad de su jurisdicción, distinguiéndolos en dos épocas: la primera con los ingresos anuales de que disponía hasta el año de 1812 en que disminuyeron; y, la segunda, los gastos que tenía en esos momentos. ${ }^{70}$

Una de las causas de tal disminución era que ni el subdelegado de Cuernavaca Miguel Cavaleri desde el año de 1816 en que entró a servir, ni el de la villa de Charo desde 1812, habían entregado los rendimientos de este ramo por causa de la guerra. Los rendimientos de Tuxtla no eran fijos como los de las demás jurisdicciones; los naturales de Toluca se resistían tenazmente a dar la contribución y en Xalapa ni siquiera se había implementado, debido al corto número de contribuyentes, pues, en el año de 1810 apenas llegaban a diecinueve. ${ }^{71}$

En lo tocante al gobierno político, si bien Charo había sido una villa con jurisdicción señorial y con la implantación del sistema de intendencias el corregidor debía entregar cuentas de la recaudación tributaria al intendente; con el establecimiento del ayuntamiento constitucional pasó a convertirse en cabecera de partido, el cual comprendía una parroquia, una vicaría, una hacienda, 42 ranchos y 1,879 almas repartidas en 3 pueblos. Precisamente, el cambio más significativo que ocurrió en Charo, después de la Independencia, fue que sus rentas comenzaron a ser administradas por dicha corporación. ${ }^{72}$

La primera preocupación de los regidores fue lo relacionado con los recursos que dispondrían para mantenerse en funciones, y para ello tuvieron que consultar a la Diputación Provincial de Valladolid

${ }^{70}$ Idem.
${ }^{71}$ Idem.
${ }^{72}$ Lejarza, Análisis, 39. 
de Michoacán, creada el primero de febrero de $1822 .{ }^{73} \mathrm{~A}$ principios de marzo de aquel año, el ayuntamiento le envió su informe relacionado con los bienes de comunidad que anteriormente habían pertenecido al Estado y Marquesado del Valle, preguntándole cómo sería su administración en lo futuro. Como respuesta, la Diputación determinó pedirle la orden que le había sido expedida anteriormente y que le explicara en virtud de qué comenzó a cobrarlos. ${ }^{74}$

Para mayo de ese mismo año, Rosel en su calidad de subdelegado y alcalde constitucional de Charo, ordenó sacar "a pública almoneda por pregones", y en un plazo de 30 días, todos los ranchos que pertenecían a los bienes de comunidad de la villa, previo avalúo de un perito, para que se verificara su arrendamiento al mejor postor. Con ello se buscaba dar cumplimiento a la circular de la Diputación Provincial de Valladolid del 15 de mayo de 1822.

Para hacer el avaluó se nombraron dos peritos: Marcelo Rocha y Máximo Pérez, quienes aceptaron el cargo. Fueron tres los pregones que Pedro Chora hizo en la plaza pública de Charo "a son de caja", invitando a hacer postura a los arrendamientos de los ranchos pertenecientes a los bienes de comunidad. ${ }^{75}$ Pedro Villaseñor, antiguo insurgente y miembro de la Diputación Provincial, fue la persona comisionada para revisar los expedientes y fue del parecer que se dieran en arriendo por 5 años, y no por 9, que era lo que pedían los postores. ${ }^{76}$

Otra de las acciones del ayuntamiento de Charo fue la realización de un censo de población que la propia Diputación ordenó que se entregara a Juan José Martínez de Lejarza, "como comisionado para la formación del plan general sobre el censo y la estadística". Lo que lla-

${ }^{73}$ El único trabajo hasta ahora es el de Carlos Juárez Nieto, "La diputación provincial de Valladolid de Michoacán, 1822-1824", en Anales del Museo Michoacano, tercera época, núm. 4 (Morelia: Consejo Nacional Para la Cultura y las Artes, Instituto Nacional de Antropología e Historia, UMSNH, junio de 1992), 129-154.

${ }^{74}$ Tavera, Actas y decretos de la Diputación, 16.

${ }^{75}$ AHMM, fondo Independiente I, Siglo XIx, exp. 7, caja 18, año 1822. Antonio Abad Rosel, sobre arrendamiento de bienes de comunidad, Charo, 7 de junio de 1822.

${ }^{76}$ AHMM, fondo Independiente I, Siglo XIX, exp. 7, caja 18, año 1822, fs. 2, 10-11v. José Ma. Ortiz Izquierdo, diputado secretario al señor alcalde primer nombrado de la villa de Charo. Valladolid, 27 de agosto de 1822. 
mó la atención de los diputados fue el hecho de que en el pueblo de Tzitzio apareciera únicamente una mujer soltera, por lo que ordenó preguntar al ayuntamiento si se habían asentado todas las edades. ${ }^{77}$

A esto habría que agregar la política implementada por el emperador Agustín de Iturbide, quien, en el segundo semestre de 1822, ordenó secuestrar una vez más los bienes de los descendientes de Hernán Cortés. Los duques de Terranova y Monteleón de Sicilia enviaron como su apoderado al conde Lucchessi para que protestara por ese acto de despojo, y no obstante que el Consejo de Estado apoyó su solicitud para levantar la orden de secuestro, éste continuó muchos años después. ${ }^{78}$

\section{Conclusiones}

Entre los años de 1809 y 1825 , la villa de Charo Matlatzinco experimentó una profunda mutación en su régimen de gobierno interno, causada por los continuos cambios en los que se vio inmersa desde la crisis política de la Monarquía española. Por un lado, tuvo mucho que ver la conducta asumida por el duque de Terranova ante la invasión francesa a la Península en 1808, lo cual llevó a los representantes del gobierno espańol a considerar esto como una traición al rey y a decretar el secuestro de sus bienes y rentas por parte de la Corona.

Por otro lado, la insurrección armada comenzada el 16 de septiembre de 1810 ocasionó la migración de las familias del campo a la ciudad; obligó a los representantes del gobierno local a obedecer a una nueva autoridad, emanada de la insurgencia; se trastornó el comercio local; y disminuyó notablemente la producción de granos en el campo a causa del robo, el saqueo y el incendio promovido por los rebeldes.

La mayor afectación, que experimentó la autoridad de aquella villa, provino de los propios diputados reunidos en Cádiz al expedir el decreto del 6 de agosto de 1811 sobre abolición de los señoríos jurisdiccionales, con lo que en poco tiempo quedó suprimido el

${ }_{77}$ Tavera, Actas y decretos de la Diputación, 17.

${ }^{78}$ Alamán, Historia, tomo v, 675. Entre los ańos de 1833 y 1834, el gobierno de Valentín Gómez Farías todavía echó mano de los bienes del duque de Terranova y el Hospital de Jesús para poner en práctica su nuevo proyecto educativo. Ibid., tomo v, 863. 
corregimiento de Charo y, con ello, el cargo de corregidor. Si bien, el régimen de gobierno en la villa parecía normalizarse con el regreso de Fernando VII al trono de España en 1814, la situación ya no fue la misma, porque el liberalismo gaditano había dejado su impronta.

Poco después de crearse el ayuntamiento constitucional en la villa de Charo en 1820, la Diputación Provincial de Michoacán la convirtió en cabeza de partido. Sin embargo, lo que parecía un cambio en el ámbito político e institucional, en realidad no lo fue tanto porque con el correr de los años, su estatus político vino a menos. Hardy señala que en 1826 el Congreso de Michoacán le concedió el título de ciudad, ${ }^{79}$ lo cual no hemos podido corroborar. En cambio, las evidencias de archivo demuestran que a pesar de que en los años subsiguientes se le siguió conociendo con el título de "villa de Charo", después de 1831 había quedado reducida a una simple tenencia que dependía del municipio de Morelia.

Por otro lado, existió cierta continuidad en cuanto al ejercicio de funciones en el gobierno local, ya que sería el antiguo corregidor y juez territorial de la villa de Charo, Antonio Abad Rosel, quien desempeñaría el empleo de subdelegado, después el de jefe de tenencia interino y por último el de alcalde cuarto del Primer Juzgado de Paz, sólo que ahora en el marco de un régimen constitucional.

Si bien estos cambios en el ámbito político fueron más perceptibles, no ocurrió igual en cuanto a los aspectos social y económico. Después de la Independencia las condiciones del lugar eran lamentables: por distintos puntos de la cabecera se podían observar casas dispersas y arruinadas; aunque los habitantes seguían viviendo de la agricultura, la cría de ganado y el pulque que expendían en la ciudad de Morelia, las ganancias eran mínimas. Por su parte, vecinos de otras localidades sujetas a Charo, como Tzitzio, por ejemplo, tenían como principal actividad productiva la fabricación de cestos, así como el comercio de cańa de azúcar, frutas y "maderas finas" que se vendían en Morelia. ${ }^{80}$

${ }^{79}$ Hardy, Viajes, 66.

${ }^{80}$ José Guadalupe Romero, Noticias para formar la estadistica del estado de Michoacán, por el Dr. D. José Guadalupe Romero, Canónigo Doctoral de la Santa Iglesia Catedral de Michoacán (México: Imprenta de Vicente García Torres, 1860), 52-54. 
No obstante, la política de "castellanización" implementada por la Corona a finales del siglo xviII en los pueblos de indios, a mediados de la centuria siguiente aún se hablaba matlatzinca o pirinda en la villa de Charo, así como en los pueblos que se hallaban situados al sureste de Morelia. ${ }^{81}$

La nueva condición de "ciudadanos" que después de la Independencia habían asumido los antiguos "vasallos" del rey o de un "señor de vasallos", quedaba bien en el papel, pero en los hechos resultó ser una ilusión. Si bien la Constitución del Estado del 19 de julio de 1825 en sus artículos preliminares 14 y 15 garantizaban el ejercicio y límites de dicha ciudadanía, ${ }^{82}$ en los libros parroquiales correspondientes a los ańos 1821-1841, los curas de Charo siguieron registrando a los recién nacidos conforme a su calidad étnica: los indios habitaban además de la cabecera, los barrios de Santiago, San Bartolomé, San Juan, San Pablo, la hacienda de La Goleta, rancho de Xaripeo y hornos de Atapaneo; los mestizos eran mayoría en pueblos como Irapeo, mientras que los mulatos se encontraban sobre todo en el rancho de Zurumbeneo y en la propia villa de Charo. Para mayo de 1831, los indios comenzaron a ser registrados como "indígenas", mientras que los blancos sólo se distinguían por ser hijos naturales o legítimos. ${ }^{83}$

\section{Archivos}

Archivo del Cabildo Catedral de Morelia (ACCM)

Archivo General de la Nación (AGN)

Archivo Histórico Casa de Morelos (АНCM)

Archivo Histórico Municipal de Morelia (Анмм)

Archivo de la Notaría Parroquial de Charo (ANPCH)

${ }^{81}$ Ibid., 52.

${ }^{82}$ Colección de Constituciones de los Estados Unidos Mexicanos, edición facsimilar de la de 1828, México, Cámara de Diputados LIx Legislatura, tomo II (México: Miguel Ángel Porrúa Grupo Editorial, 2004), 7-8.

${ }^{83}$ ANPCH, Bautismos, lib. 10, años 1809-1834, "Libro en que se asientan...", $\mathrm{f}$. $229 \mathrm{v}-230$ y ss.; Bautismos, lib. 11, años, 1834-1841, "Libro en que se escriben las partidas de bautismos de indios y demás castas de esta villa de Charo desde el día $1^{\circ}$ de octubre de 1834 ", f. 89 y ss. 
Archivo Parroquial del Sagrario Metropolitano de Morelia (APSMM) Centro de Estudios de Historia de México-Carso (CEHM-Carso)

Bibliografía

Alamán, Lucas. Historia de Méjico. Desde los primeros movimientos que prepararon su independencia en el año de 1808 hasta la época presente. Colección Clásicos de la Historia de México. 5 tomos. Edición facsimilar de la de 1849-1952. Precedido de "Alamán historiador” por Moisés González Navarro. México: Fondo de Cultura Económica, Instituto Cultural Helénico, 1985.

Alanís Boyso, José Luis. Corregidores de Charo. Apuntes para su estudio 1590-1810. Colección Biblioteca Enciclopédica del Estado de México. Toluca: Editorial Libros de México, 1976.

Benson, Nettie Lee. La diputación provincial y el federalismo mexicano. Serie Estudios Parlamentarios, núm. 1. México: Cámara de Diputados Li Legislatura, 1980.

Bustamante, Carlos María de. Los tres siglos de Méjico durante el gobierno español hasta la entrada del Ejército Trigarante. Obra escrita en Roma por el padre Andrés Cavo, de la Compañia de Jesús. Publicada con notas y suplemento por el licenciado... México: Imprenta de J. R. Navarro, Editor, 1852.

Castro, Concepción de. La revolución liberal y los municipios españoles. Madrid: Alianza Editorial, 1979.

Colección de Constituciones de los Estados Unidos Mexicanos. Edición facsimilar de la de 1828. 3 tomos. México: Cámara de Diputados LIx Legislatura, Miguel Ángel Porrúa Grupo Editorial, 2004.

Colección de los decretos y órdenes de las Cortes de España que se reputan vigentes en la República de los Estados Unidos Mexicanos. Edición facsimilar de la de 1829. Estudio introductorio de Óscar Cruz Barney. México: Suprema Corte de Justicia de la Nación, 2005.

Colección de los decretos y órdenes que han expedido las Cortes Generales y Extraordinarias desde su instalación en 24 de septiembre de 1810 hasta igual fecha de 1811. Cádiz: Imprenta Real, 1811.

Chust, Manuel. La cuestión americana en las Cortes de Cádiz. Bi- 
blioteca Historia Social, núm. 2. Valencia: Centro Francisco Tomás y Valiente unEd Alzira-Valencia, UnAM, 1999.

Enciso Alonso-Muñumer, Isabel. Las Cortes de Cádiz. Historia del mundo para jóvenes/ serie: Historia de España. Madrid: Ediciones Akal, 1999.

García MarTínez, Bernardo. El Marquesado del Valle. Tres siglos de régimen señorial en Nueva España. Colección Nueva Serie, núm. 5. México: El Colegio de México, 1969.

GuzMán Pérez, Moisés. Miguel Hidalgo y el gobierno insurgente en Valladolid. Colección Bicentenario de la Independencia, núm. 9. Tercera edición actualizada. Morelia: Instituto de Investigaciones Históricas, UMSNH, 2011.

. La Suprema Junta Nacional Americana y la Independencia. Ejercer la soberanía, representar la nación. México: UMSNH, Gobierno del Estado de Michoacán, Consejo Nacional para la Cultura y las Artes, 2011.

. El insurgente José Maria Guadalupe Salto. Vida y martirio. Colección Bicentenario de la Independencia, núm. 15. México: Secretaría de Cultura, Gobierno del Estado de Michoacán, Secretaría de Turismo y Cultura, H. Ayuntamiento de Morelia, Instituto de Investigaciones Históricas, UMSNH, 2012.

Hardy, R. W. H. Viajes por el interior de México en 1825, 1826, 1827 y 1828. Colección Linterna Mágica, núm. 23. Presentación de Ernesto de la Torre Villar. México: Editorial Trillas, 1997.

Hernández y Dávalos, Juan E. Colección de documentos para la historia de la guerra de independencia de México de 1808 a 1821. Edición facsimilar de 1877-1882. 6 tomos. México: Instituto Nacional de Estudios Históricos de la Revolución Mexicana, Comisión Nacional para las Celebraciones del 175 Aniversario de la Independencia Nacional y 75 Aniversario de la Revolución Mexicana, 1985.

Juárez Nieto, Carlos. "La diputación provincial de Valladolid de Michoacán, 1822-1824”. En Anales del Museo Michoacano. Tercera época. Núm. 4. Morelia: Consejo Nacional Para la Cultura y las Artes, Instituto Nacional de Antropología e Historia, UMSNH, junio de 1992, 129-154. 
- El proceso político de la independencia en Valladolid de Michoacán, 1808-1821. Morelia: Secretaría de Difusión Cultural y Extensión Universitaria, Instituto de Investigaciones Históricas, UMSNH, Centro Regional Michoacán del INAH, 2008.

Martínez de Lejarza, Juan José. Análisis estadístico de la provincia de Mechuacan en 1822. Reedición correspondiente a la primera de 1824. Morelia: Fimax Publicistas, 1974.

Romero, José Guadalupe. Noticias para formar la estadística del estado de Michoacán, por el Dr. D. José Guadalupe Romero, Canónigo Doctoral de la Santa Iglesia Catedral de Michoacán. México: Imprenta de Vicente García Torres, 1860.

Serrano Ortega, José Antonio. "Las herencias ilustradas y gaditanas en tiempos del absolutismo Nueva España (1814-1819)". En El sexenio absolutista. Los últimos años insurgentes Nueva España (1814-1820), coord. José Antonio Serrano Ortega, 191-227. México: El Colegio de Michoacán, 2014.

Tavera Alfaro, Xavier. Actas y decretos del Congreso Constituyente del Estado de Michoacán 1824-1825. 2 tomos. Compilación, prólogo y notas de Xavier Tavera Alfaro. Morelia: UMSNH, 1975. . Actas y decretos de la Diputación Provincial 1822-1823. Estudio introductorio de Xavier Tavera Alfaro. Morelia: H. Congreso del Estado de Michoacán, 1989.

Terán, Marta. "Gobiernos indígenas en los pueblos michoacanos al final de la Colonia”. En Gobierno y economía en los pueblos indios del México colonial. Colección Científica, coord. Francisco González-Hermosillo Adams, 213-231. México: INAH, 2001. 